\title{
ALGUNS ASPECTOS DA EDUCAÇÃO NA SOCIEDADE DA INFORMAÇÃO
}

\section{Artur Martins Cabugueira*}

\begin{abstract}
O presente artigo, constitui um contributo para a caracterização da sociedade tecnológica ou sociedade da informação, na qual vivemos emersos nos mais diversos aspectos e com os quais temos de saber operar para poder "sobreviver", dando enfoque ao problema da infoexclusão, dadas as disparidades no acesso às novas tecnologias por parte dos diferentes países e, dentro de cada país, por parte dos diferentes sectores económicos e sociais.

Apresentamos, de seguida, alguns argumentos para defender a utilização das novas tecnologias no campo educativo, embora também coloquemos em relevo alguns eventuais efeitos negativos dessa mesma utilização.

Terminamos com a abordagem duma questão que hoje em dia ganha uma cada vez maior acuidade: a questão do "novo" papel do professor na sociedade tecnológica em que vivemos - as tecnologias poderão vir a substituir a figura do professor? O professor manterá as suas funções tradicionais ou o seu papel sofrerá mudanças profundas em adaptação à nova realidade?
\end{abstract}

\section{CARACTERIZAÇÃO}

A tecnologia invadiu definitivamente as nossas vidas.

Aos níveis mais elementares do nosso quotidiano, vemo-nos rodeados dos mais diversos sistemas técnicos. Vivemos em espaços organizados, alimentamo-nos de comida enlatada, usamos energia na forma de electricidade, gás, gasolina ou solar, servimo-nos de diferentes veículos de transporte, utilizamos diversos equipamentos domésticos como o frigorífico, máquinas de lavar, secar, o micro-ondas, a televisão, o vídeo,

\footnotetext{
${ }^{*}$ Universidade de Trás-os-Montes e Alto Douro
} 
o computador. Em suma, onde quer que nos encontremos, os produtos da tecnologia invadem as nossas casas, as nossas escolas, os nossos locais de trabalho, envolvendo completamente as nossas vidas.

A este propósito Azevedo (1991: 87) fala no "oceano tecnológico" que rodeia o homem de hoje, dizendo ser um oceano estranho onde a grande maioria voga à deriva, incapaz de conhecer os principios, de dominar os meios e de determinar as finalidades.

Pode-se argumentar que todos os aspectos antes referidos relativamente à "invasão tecnológica" não são exclusivos do nosso tempo. Efectivamente a história da Humanidade é feita duma contínua invenção de objectos e sistemas tendo como finalidade a satisfação das necessidades básicas do homem. Assim, neste sentido, e de acordo com o Relatório da UNESCO (1981), a tecnologia, enquanto meio de alargar as capacidades biológicas do homem, é uma realidade universal. Embora seja reconhecido que a tecnologia tem sido o principal instrumento responsável pela criação da nossa civilização, também é verdade que é possível encontrar hoje factores únicos que conferem uma especial importância à tecnologia no mundo moderno.

Para além das necessidades de sobrevivência (alimentação, vestuário, habitação, saúde e segurança), de desenvolvimento (educação, emprego) e de afirmação (riqueza, estabilidade e crescimento), o homem também precisa de um propósito, de uma direç̧ão, de uma perspectiva de mudança para melhor - uma visão optimista do futuro (Baez et al. cit. por Reis, 1995: 22). Ora é para a tecnologia que o homem se volta quando pretende produzir tais mudanças. Vivemos, de facto, num período de rápidas e profundas mudanças e a nossa sociedade tecnológica parece ser qualitativamente diferente das outras que a precederam.

Falamos em sociedade tecnológica ao referirmo-nos à sociedade actual, dada a preponderância da tecnologia; outros designam-na por sociedade de informação. Mas, o que se entende, mais concretamente; por sociedade tecnológica ou sociedade da informação?

Para Azevedo (in: Marques, et al. 1998: 7) quando falamos de sociedade da informação (S.I.) estamos a referir-nos a uma enorme variedade de temas. Entre outros, o autor refere os seguintes aspectos:

- as imensas capacidades das telecomunicações derivadas da aplicação das novas tecnologias (N.T.);

- $\quad$ as enormes quantidades de informação em casa;

- a robotização da indústria, da automatização dos escritórios, da edição electrónica, dos recursos de ensino à distância, o software educativo multimédia, as compras e negócios realizados por meios electrónicos, os novos meios de tratamento da imagem, as bases de dados, o tele-trabalho, a videoconferência, as redes de comunicação. 
Azevedo considera ainda como um aspecto característico da S.I. o excesso de informação, da dificuldade em a compreender e integrar e da rapidez com que a esquecemos.

Efectivamente, graças à utilização das N.T. estamos prestes a assistir a uma verdadeira revolução que afecta tanto as actividades ligadas à produção e ao trabalho como as ligadas à educação e formação.

A maior parte dos sistemas tecnológicos invadiu, como já referimos, uma boa parte dos lares do mundo industrializado e é utilizada por um número crescente de pessoas nos países em desenvolvimento. Tudo indica que o impacto das N.T. ligadas ao desenvolvimento das redes informáticas se vai alargar muito rapidamente a todo o mundo.

Para Castilho (1999: 18) a substituição da sociedade industrial pela sociedade da informação é legitimada pela substituição de uma pressão, que vinha do trabalho na sociedade industrial, por outra pressão, que vem do conhecimento na sociedade da informação.

$\mathrm{O}$ autor refere-se à importância da informação e do conhecimento nos seguintes termos: aquilo que hoje identifica o valor acrescentado da nossa produtividade e constitui a mola impulsionadora do desenvolvimento é o conhecimento e a inteligência....

E noutra passagem afirma: ... deslocação do núcleo da economia: os poderosos da época industrial detinham capital, com que arregimentavam a força de trabalho para produzir em série; os poderosos da sociedade da informação precisam de informação e saber para fazer a mesma coisa.

No dizer de Drucker (cit. por Castilho, 1999: 18) ... a produtividade do conhecimento já se tornou a chave da produtividade, a força da competitividade e o sucesso económico. $O$ conhecimento tornou-se já a indústria primeira, a que fornece à economia os requisitos essenciais à produção.

O computador pessoal, ligado através duma simples rede telefónica a outros computadores, formando redes cada vez mais complexas, abriu as portas à interactividade, cedendo o espaço ao tempo como factor estratégico.

A interactividade possibilitou um novo modelo de comunicação, no qual cidadãos intervenientes simultaneamente interagem directamente com a fonte de informação e em que são eles mesmos fontes de informação.

Com o advento da S. I., afirma-se um outro modelo de pensamento: verifica-se $\mathrm{o}$ crescimento dum pensamento por possibilidades, conduzindo ao reforço da diversidade e da individualização, inversamente à uniformidade e massificação, as características mais importantes dos tempos da pré-Sociedade de Informação. 
Para terminar este ponto achamos de interesse fazer uma referência à visão de Carneiro (1999: 478-479) sobre este assunto. Afirma o autor que foi só há relativamente pouco tempo que começámos a ter a noção da mudança de paradigma da chamada sociedade industrial para a sociedade pós-industrial - agora também chamada sociedade da informação, sociedade do conhecimento ou sociedade cognocrática - onde o conhecimento é mais importante do que a mera acumulação de capital financeiro e de capital fisico para o progresso dos povos.

Se na sociedade industrial sempre tinha sido a tecnologia a comandar as modificações mais substanciais (a máquina a vapor, a electricidade, os novos meios de comunicação, a televisão, o fax, o computador, a Internet), agora, graças às novas tecnologias de informação e da comunicação - miniaturizadas, amigáveis, baratas - passou a haver, pela primeira vez, um domínio de tecnologia e não um mero usufruto.

Para Carneiro (1999: 478) uma das características mais importantes da actual tecnologia é que ela permite a difusão de muitos para muitos: todos podem ser fornecedores de conteúdo na Internet, todos são interactivos, todos são multimédia. Passámos de uma geração constituída por uns poucos emissores - detentores dos meios tecnológicos - e por uma multidão de fruidores, para uma sociedade onde a tecnologia - do telefone celular ao computador pessoal - é democratizada, no sentido da sua activa apropriação.

Em conclusão podemos afirmar que as sociedades actuais são pois, todas, pouco ou muito, sociedades da informação, nas quais o desenvolvimento das tecnologias pode criar um ambiente cultural e educativo susceptível de diversificar as fontes do conhecimento e do saber.

\subsection{Disparidade de acesso às novas tecnologias}

O problema da disparidade de acesso às novas tecnologias de informação e comunicação pode colocar-se em termos de desigualdade de acesso entre países (ou grupos de países), sectores económicos e sociais.

De acordo com o Relatório Mundial de Educação (1998: 109) as perspectivas de utilização das N.T. no campo da educação são ensombradas, à escala mundial, pelas disparidades de acesso a estas tecnologias. Na maioria dos países não existem as infra-estruturas básicas necessárias para aceder a elas. Em todo o Continente Africano, por exemplo, existem pouco mais telefones do que na cidade de Tóquio. A maioria das escolas do mundo ainda não tem electricidade.

Os países em desenvolvimento enfrentam vários problemas para fazer face ao acesso e uso das tecnologias de informação e comunicação. Entre outros, alguns desses problemas colocam-se no que se refere: 
a) Os preços de equipamentos, software e telecomunicações, os quais são muito mais altos nesses países relativamente aos países avançados;

b) Falta de tradição nesses países de envolvimento activo do sector privado em apoio a causas educacionais e/ou sociais, como acontece em muitos países desenvolvidos;

c) A revolução de Internet atingiu esses países sem que a fase anterior de informação tenha efectivamente ocorrido e frutificado, como aconteceu nos países desenvolvidos durante as décadas de 80 e 90 .

A UNESCO (Relatório Mundial de Informação, 1997) tem manifestado a sua preocupação pelos perigos do alargamento do fosso entre países "ricos em informação" e "pobres em informação". Nesse Relatório é dado a conhecer com detalhe o panorama das disparidades actuais em recursos informativos entre todas as regiões do mundo.

A figura 1 mostra uma selecção dos indicadores relativos aos media e à comunicação.

Fig. 1 - Indicadores dos Media e das Comunicações, por região, 1995
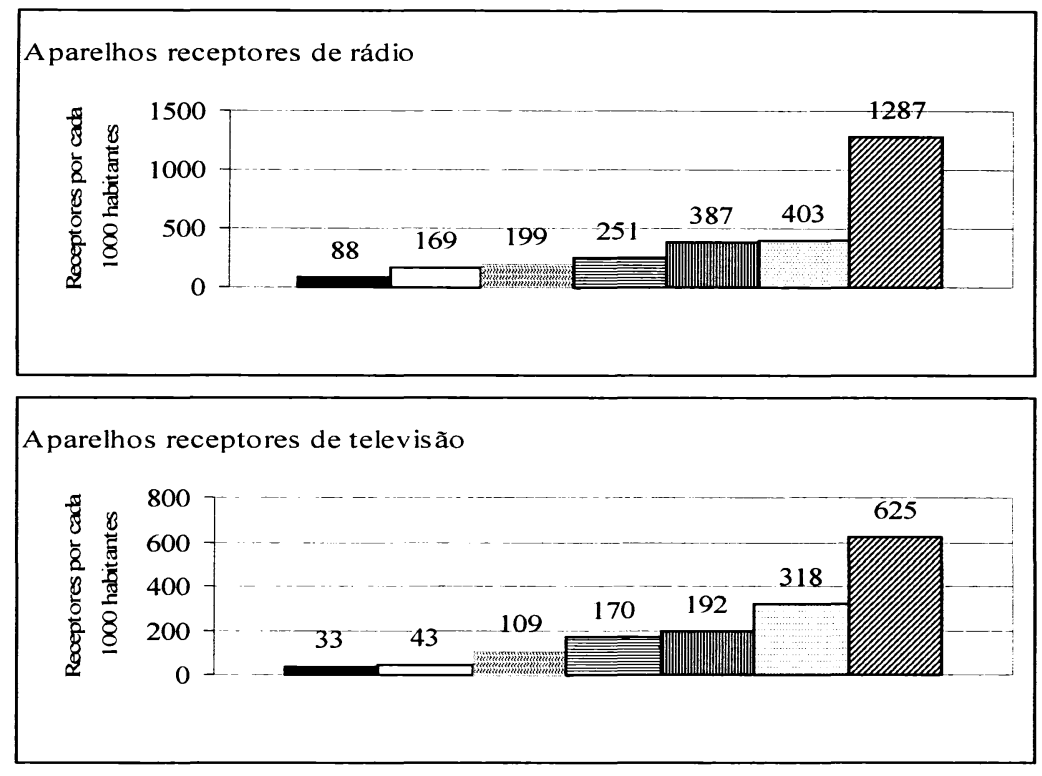
A frica Subsariana
$\square$ Estados A rabes
Sulda Ásia
国 $\mathrm{mérica} \mathrm{Latina/C} \mathrm{araíbas}$
A Ásia Oriental/O ceânia
$\square$ Paises em Transição
Regiòes mais desenvolvidas 

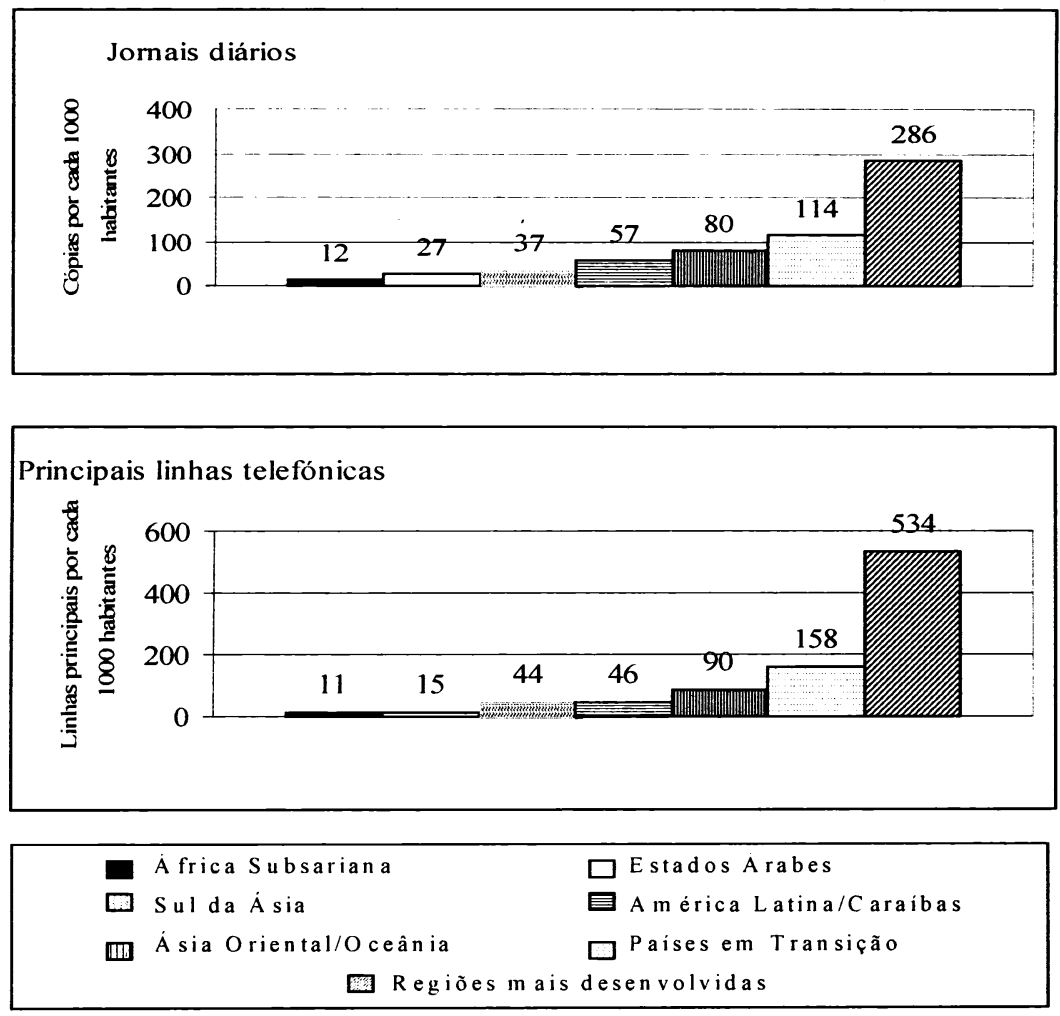

Fonte: Relatório Mundial de Educação, 1998

Mas, também no que se refere aos diferentes sectores económicos e sociais, a utilização das N.T. não é uniforme. Particularmente o sector da educação tem tido poucos incentivos e possibilidades limitadas para a aquisição de novas tecnologias, fundamentalmente devido aos constrangimentos orçamentais.

A utilização do computador para fins educativos ainda se encontra numa fase experimental, enquanto noutros sectores a sua utilização alterou já processos técnicos essenciais. Como muito bem sublinha Marques, R. (1998: 14-18) a sociedade da informação, se construida tendo como prioridade a dimensão humana, não pode gerar novas exclusões sociais ou acentuar as já existentes. A Escola pode e deve ser o principal espaço de afirmação deste paradigma. A sociedade da informação não deve permitir a criação, ou o reforço de predominâncias culturais, ideológicas ou económicas de alguns protagonistas, defendendo, ao invés, a diversidade e a interdependência entre as 
comunidades. Como espaço de liberdade, deverá estimular o diálogo na diversidade, a partilha de recursos culturais e a afirmação de cada pessoa, povo ou cultura. Os primeiros passos de sociedade da informação, ainda em fase de afirmação, devem acentuar o carácter democrático e solidário da sua essência, sendo útil que os projectos mais relevantes se afirmem de utilidade evidente e universal, bem como de fácil acesso. Ainda de acordo com o autor uma das maiores interrogações que estão no horizonte próximo, no quadro da sociedade da informação, é a ameaça da infoexclusão.

Com isto pretende dizer que o curso da história caminha para um ponto em que não saber operar com tecnologias de informação e comunicação será equivalente ao analfabetismo funcional. Quem aí se deixar fixar terá uma enorme desvantagem competitiva ao nível do emprego e da cidadania.

Ora, o que acontece efectivamente no nosso país, (como em muitos outros) é que o nível de literacia tecnológica básica é baixíssimo, pelo que se corre o risco de um grande número de pessoas não ter a "carta de condução" para as auto-estradas da informação, ficando, portanto, à margem.

A educação articula-se com a Sociedade de Informação, dado basearse na aquisição, actualização e utilização dos conhecimentos. Nesta sociedade emergente multiplicam-se as possibilidades de acesso a dados e a factos. Assim, a educação deve facultar a todos a possibilidade de terem ao seu dispor, recolherem, seleccionam, ordenarem, gerirem e utilizarem essa enorme informação.

A Sociedade de informação corresponde, assim, a um duplo desafio para a democracia e para a educação. Cabe ao sistema educativo fornecer, a todos, meios para dominar a proliferação de informações, de as seleccionar e hierarquizar, com espírito crítico, preparando-os para lidarem com uma quantidade enorme de informação que poderá ser efémera e instantânea.

Sintetizando, terminamos este ponto, deixando três ideias fundamentais:

1 - A sociedade da informação, se construída tendo como prioridade a dimensão humana, não pode gerar novas exclusões sociais. Deve, pelo contrário, servir para anular ou minorar algumas das existentes;

2 - A idade, o sexo ou o nível sócio-económico não devem ser limites ou obstáculos no acesso e no usufruto da sociedade da informação. Particularmente, no que diz respeito à disponibilidade ou não de meios financeiros para aceder às novas tecnologias, a sociedade da informação não pode cavar mais o fosso entre ricos e pobres, dado que a informação é a maior riqueza do século XXI, daí resultando ricos cada vez mais ricos e pobres cada vez mais pobres; 
3 - As N.T., tal como outros bens essenciais como a saúde e a educação, devem ter um acesso universal e facilitado em espaços públicos devidamente equipados (escolas, bibliotecas, associações culturais, sindicatos, etc.).

\subsection{A Educação face à nova realidade social - o papel da tecnologia na educação do séc. XXI.}

A utilização pedagógica das tecnologias de informação e comunicação não constitui um facto novo: por exemplo a rádio educativa aparece já antes da primeira guerra mundial. De acordo com Fowell (1996: 63) as tecnologias de informação são usadas no ensino há mais de vinte anos, conhecendo um maior desenvolvimento nos anos 80 com o aparecimento dos computadores pessoais, mais acessiveis, e com o aperfeiçoamento das redes de telecomunicações.

Porém, não foi só a gama das tecnologias usadas que se alterou com o tempo, foi também a vontade de alcançar um público mais vasto, para além do sistema escolar formal, desde o pré-escolar até à terceira idade que é no fundo, o objectivo do ensino "para toda a vida".

A utilização das tecnologias de informação e comunicação no ensino à distância, já muito comum, constituiu uma primeira via promissora para todos os países, recorrendo a vectores muito diversos: cursos por correspondência, rádio, televisão, suportes audiovisuais, ensino por telefone ou teleconferências. No ensino superior, e lado a lado com os esquemas de desenvolvimento universitário, o ensino à distância está hoje a retirar vantagens dessa realidade.

O sucesso da educação à distância em diferentes partes do mundo demonstra a capacidade para ministrar programas educativos de grande qualidade sem que os estudantes precisem de frequentar aulas ou, sequer, estar presentes na universidade, face a face com os professores.

As instituições de ensino à distância e os seus programas são um bom exemplo da fusão entre as tecnologias de informação e comunicação há muito estabelecidas e as suas congéneres da actualidade (Skilbeck, 1998: 40).

O primeiro e talvez mais fundamental impacto de T. I. C. na educação foi ocasionado pelo advento dos computadores e a sua espantosa multiplicação das capacidades de processamento numérico (exemplo: previsão meteorológica), e de processamento simbólico/lógico (exemplo: edição de texto). Uma outra capacidade relaciona-se com a comunicação que veio ampliar o impacto dos computadores em 2 vertentes: a) A interacção multimédia e a instrumentação de dispositivos fisicos, abrindo possibilidades para inovação nas imagens, sons, etc. b) $A$ interligação de 
computadores e pessoas em locais distantes, abrindo novas possibilidades de relação espaço - tempo entre educadores e educandos.

Nos anos 90 assistiu-se, fundamentalmente no ensino superior, a um crescente interesse pelas tecnologias de informação e comunicação, o que se deve sobretudo ao aumento do número de alunos, a procura por parte dos empregadores de licenciados com conhecimentos na área dessas tecnologias e também pelas amplas oportunidades proporcionadas pelo uso da Internet.

De sublinhar que quando falamos de tecnologias de informação e comunicação nos estamos a referir às tecnologias relativamente acessíveis, assim como aos computadores pessoais com aplicações multimédia, à aplicação de redes de telecomunicações e ao acesso à Internet.

Sendo já utilizadas com sucesso no contexto da formação contínua ministrada no seio das empresas, tudo indica que as novas tecnologias desempenharão um papel de crescente relevância na educação de adultos, de acordo com as condições próprias de cada país.

Há quem sugira que a escola tal como hoje a concebemos, não voltará mais a ser necessária, podendo perfeitamente existir uma relação directa entre os alunos $\mathrm{e}$ as fontes de informação sem necessidade de intermediários como acontece com os actuais sistemas educativos. Fará algum sentido esta visão?

De facto, na actualidade por todo o mundo, e independentemente das suas escolas e dos seus professores, os estudantes têm acesso às fontes de informação a partir das suas próprias casas, dos seus locais de trabalho, das bibliotecas, etc.

A propósito da questão colocada, está também outro fenómeno já em desenvolvimento no nosso tempo - o ciberespaço e o tempo virtual, em substituição do espaço material e do tempo real.

As salas de aula, as aulas e as conferências virtuais são, já hoje, uma realidade pondo frente a frente estudantes, teclados e ecrãs.

Nesta linha de pensamento Carlos Tedesco (1999: 22) afirma que a utilização das N.T. obriga à modificação de conceitos básicos como o de tempo e de espaço. A própria noção de realidade começa a ser repensada, a partir das possibilidades de construir realidades "virtuais" que colocam problemas inéditos $e$ interrogações de ordem epistemológica.

Por outro lado, o impacto das tecnologias de informação e comunicação coloca a necessidade de se por em marcha um amplo processo de revisão curricular em todos os níveis e áreas.

No nível médio, surgiram novas profissões com a difusão das tecnologias de informação e comunicação, particularmente a Internet, como por exemplo o Projectista de Web, Administrador de redes, etc. 
No nível de graduação alguns currículos estão irremediavelmente obsoletos. Os cursos de formação de professores (licenciaturas) necessitam de uma injecção de competências ao nível do uso da T.I.C., de forma a contemplar a formação de professores familiarizados com o uso dessas novas tecnologias. Também se poderá colocar a questão relativamente à necessidade de um curso de pós-graduação específico no uso das T.I.C. na educação, para formar professores nessa área para os diversos cursos de formação de professores.

Finalmente, no nível de pós-graduação em T.I.C., uma dúvida levantada em muitos países refere-se à necessidade de se acelerar a formação de especialistas, não só para fazer face às necessidades do mercado em termos numéricos, mas principalmente para se adequar à velocidade da evolução das T.I.C.

Ainda neste sentido não podemos deixar de fazer referência às interessantes ideias de Roberto Carneiro sobre esta problemática.

$\mathrm{O}$ autor falando sobre a geração actual a que chama de geração click (a que nasceu com o rato do computador na mão) e da geração anterior a que chama de geração zap (a que se mantinha passiva perante o televisor com o controlo remoto na mão, mudando continuamente de programação), escreve: A geração click (...), é manifestamente diferente por ser mais interactiva e "instantânea" que a geração zap precedente. A escola continua a ser zap, mas a juventude é click (Carneiro, 1999: 479).

Embora, naturalmente, defendamos a introdução das N.T. na educação, achamos (emitindo, assim, a nossa opinião relativamente à questão anteriormente colocada), que não conseguimos ver que tais tecnologias venham a revolucionar de tal forma os sistemas educativos, ao ponto de substituir completamente os intermediários entre os alunos e as fontes de informação.

As salas de aula virtuais não deverão substituir as salas de aulas reais, porque estas sustentam muito mais actividades do que aquelas.

Concordamos, assim, com Skilbeck (1998: 39) quando afirma que $a$ sala de aula real para além dum simples local de encontro para processamento de informação é um lugar que promove relações, cultiva valores, impõe normas, disponibiliza um forum para a discussão critica, estimula e motiva e serve como um modelo de comunidade humana.

Portanto, a sala de aula virtual não é capaz de compreender aquele conjunto de interacções e processos de desenvolvimento complexos a que chamamos educação. Esta questão relaciona-se também com o (novo) papel dos professores na sociedade de informação, tema que abordaremos noutro local do nosso trabalho.

Em suma, pode-se afirmar que a introdução das N.T. nos sistemas educativos se traduz num desafio decisivo sendo importante que a escola 
e a Universidade se encontrem no centro desta profunda transformação que afecta o conjunto da sociedade.

\subsection{Argumentos utilizados para defender a utilização da tecnologia na educação}

Existem várias razões pelas quais as tecnologias de informação são introduzidas no ensino.

Para Fowell, (1996: 64) há duas importantes razões para a aplicação das tecnologias de informação na educação: 1 . O aumento do número de estudantes no ensino superior tem provocado importantes mudanças na organização do ensino/aprendizagem e na própria avaliação, uma vez que não tem sido acompanhado com o respectivo aumento do staff de ensino. Como consequência houve necessidade de adoptar novos métodos, cabendo às tecnologias da informação o papel de aliviar a pressão que recai sobre esse staff de ensino; 2 . A capacidade que as tecnologias da informação possuem para aperfeiçoar a aprendizagem dos alunos, pelo facto de proporcionarem aos estudantes oportunidades de desenvolver as competências exigidas pelas chefias ou pelo facto de criarem o ambiente necessário à aprendizagem.

Segundo o Relatório para a UNESCO da Comissão Internacional sobre Educação para o século XXI (1996), as novas tecnologias oferecem, como instrumentos de educação de crianças e adolescentes, uma oportunidade sem precedentes de responder com toda a qualidade necessária a uma procura cada vez mais intensa e diversificada. As possibilidades e vantagens que apresentam no campo pedagógico são consideráveis, ainda de acordo com o Relatório.

Em especial o recurso ao computador e aos sistemas multimédia permite traçar percursos individualizados em que cada aluno pode progredir de acordo com o seu ritmo. Oferecem igualmente aos professores a possibilidade de organizar mais facilmente as aprendizagens em turmas de nivel heterogéneo. $\mathrm{O}$ recurso às novas tecnologias constitui, também, um meio de luta contra o insucesso escolar, já que se observa, muitas vezes, que alunos com dificuldades no sistema tradicional ficam mais motivados quando têm oportunidade de utilizar essas tecnologias e podem, deste modo, revelar melhor os seus talentos.

Waddington (cit. por Reis, 1995: 26) refere que hoje, a educação é indiscutivelmente um elemento-chave na promoção mas também no controlo de uma sociedade assente no desenvolvimento tecnológico. Sendo a educação um empreendimento orientado para a invenção do futuro, a gestão dos currículos escolares tem de ter como objectivo não só 
os aspectos contemporâneos mas, de uma forma essencial, a preparação do futuro.

Assim, existem duas razões básicas para integrar o estudo dos temas tecnológicos na educação. Em primeiro lugar os jovens têm de ser educados de forma a aumentar o pelotão de reserva da ciência e da tecnologia, constituindo, através deste meio, uma bolsa de recursos necessários para garantir a continuidade do desenvolvimento actual (Burke, cit. por Reis, 1995: 26). Em segundo lugar, a Educação Tecnológica deve facultar a todos os jovens uma informação básica e promover a formação de uma consciência que os prepare para viverem numa sociedade tecnológica como seres humanos livres, capazes de formar e influenciar decisões, as quais, em muitos casos, podem marcar o futuro de forma irreversível (UNESCO, 1981; Burke, 1987; Waddington, 1987, cit. por Reis, 1995: 26).

Além de propiciar uma rápida difusão de material didáctico e de informação de interesse para pais, professores e alunos, as novas tecnologias permitem, entre outras possibilidades, a construção interdisciplinar de informações produzidas individualmente ou em grupo por parte dos alunos, colaboração no desenvolvimento por parte de alunos geograficamente dispersos, bem como a troca de projectos didácticos entre educadores das mais diferentes regiões do país. A medida que as velocidades de transmissão das redes vão aumentando, vão-se tornando visíveis novas aplicações para fins educacionais, tais como laboratórios virtuais. Figueiredo (1995: 3) defende que os benefícios da Internet e outras redes electrónicas serão tripartidos: para os alunos, professores e para as escolas. Para os alunos por exemplo, "permitem aos jovens explorar - em vários contextos de aprendizagem, bem como nos seus tempos livres - as múltiplas facetas dos acessos e navegação em redes de dados, oferecendo uma excelente oportunidade para os familiarizar com a actual transferência de muitas actividades profissionais para o ciberespaço.

Os professores, entre outros benefícios, poderão "partilhar e construir colectivamente exemplos de boa prática e ideias para o tratamento de pontos específicos de matéria, e podem obter, a partir do mundo do trabalho, excelentes casos de estudo para a exploração na sala de aula". Finalmente, "para além dos professores e alunos, também as próprias escolas terão muito a ganhar com a sua ligação às redes de dados. Cada escola poderá criar o seu ambiente virtual próprio e torná-lo acessível tanto interna como externamente".

Em suma, achamos que, indubitavelmente a utilização das novas tecnologias irá constituir um instrumento muito importante no processo de aprendizagem, sendo, aliás a sua presença já hoje um facto 
consumado, mas o seu uso não pode ser um fim em si mesmo, mas uma função do desenvolvimento cognitivo.

Examinemos no ponto seguinte alguns problemas que se podem levantar relativamente à utilização de novas tecnologias na educação.

\subsection{Consequências da introdução das novas tecnologias no campo da educação}

Examinámos, ponto anterior, alguns dos argumentos utilizados para defender a utilização da tecnologia na educação. Vimos, de que forma todos apontavam para as vantagens dessa utilização.

Contudo, não querendo de modo nenhum, negar tais vantagens e potencialidades, pretendemos também fazer uma referência a alguns problemas ou aspectos menos positivos que as tecnologias de informação e comunicação podem ter implícitos.

Embora se esteja ainda muito longe de conhecer todas as potencialidades educativas das N.T., sem dúvida que o seu impacto sobre os sistemas educativos será muito maior do que as tecnologias anteriormente utilizadas na educação.

Segundo o Relatório Mundial de Educação (1998: 127) esse impacto observar-se-á a dois níveis: na natureza e no tipo de materiais didácticos ao dispor dos alunos e nos métodos educativos. No que se refere aos primeiros, as tendências actuais indicam que os livros podem vir a ser cada vez mais complementados com software informático multimédia na apresentação das matérias habituais de programa. O problema que se levanta, no entanto, relaciona-se com as grandes limitações tanto no que diz respeito às capacidades do stock de computadores nas escolas como à existência de software adequado que possa ser directamente integrado nos currículos actuais.

A questão dos métodos e abordagens pedagógicas também se reveste de alguma complexidade. $O$ que acontece é que mesmo quando não existam falta de computadores e outros equipamentos, a possibilidade de pôr em prática metodologias alternativas esbarra com constrangimentos provocados pelos estabelecimentos escolares e pelos currículos existentes. A maioria das escolas nos países industrializados não foi concebida para receber tecnologias de informação e comunicação. A experimentação de métodos e abordagens pedagógicas alternativas à educação formal tem, por isso, vindo a ser restringida a projectos-piloto em escolas tradicionais.

Para Carlos Tedesco (1999: 82) a presença das novas tecnologias na educação apresenta um novo problema, que é o facto de o seu desenvolvimento produzir um fenómeno de acumulação de conhecimentos 
nos circuitos por eles dominados. $O$ que não estiver incluido nesses circuitos, terá uma existência precária (...).

Concordamos com o autor quando refere mais dois problemas relativos à inclusão das N.T. na educação. O primeiro relaciona-se com o custo do acesso às N.T., já que não se trata apenas do custo inicial, mas também do custo posterior à incorporação das tecnologias (manutenção, actualização constante dos equipamentos e do software, etc.) Também Fowell (1996: 65) se refere aos custos das tecnologias da informação para educação, como sendo um factor limitativo do seu sucesso na escola. Escreve o autor: a maior preocupação para os que estão envolvidos no projecto e gestão da educação, é o custo da aplicação das tecnologias da informação. Estes custos não são insignificantes.

O segundo problema, que é sublinhado também por muitos outros autores e por nós próprios, diz respeito ao facto das N.T. redefinirem o problema da convivialidade, já que uma característica comum a todas elas é o trabalho individual e mediatizarem as relações entre pessoas através de ecrãs, cartões pessoais ou outros meios.

Esta revolução tecnológica cria formas novas de socialização e até mesmo, novas definições de identidade individual e colectiva. A expansão das N.T. e das redes informáticas, embora favorecendo a comunicação com o outro (à escala mundial), reforça ao mesmo tempo as tendências de cada um para se fechar sobre si mesmo e se isolar. O desenvolvimento do trabalho à distância, a proliferação de actividades de lazer, que mantêm o indivíduo isolado frente ao computador faz surgir alguns receios - o acesso ao mundo virtual que pode, segundo alguns, levar a uma perda do sentido da realidade.

A sobre-informação veiculada pela Internet e, fundamentalmente, a certificação do rigor na imensidão das fontes de informação, acentuam a importância dos educadores na formação de cidadãos com espírito crítico de forma a não se perderem no labirinto virtual.

Outra preocupação relaciona-se com a diversidade, ou seja, a necessidade de existência de um software que possibilite a cada nacionalidade, usando o mesmo suporte, se possa expressar na sua própria língua. É fundamental que cada civilização aposte numa indústria de conteúdos que espelhe a riqueza de cada povo, contrariando, desta forma, a hegemonia de determinadas culturas, sobre outras.

Terminamos este ponto fazendo nossas as palavras de Carlos Tedesco (1999: 84): as tecnologias oferecem-nos informação e possibilitam a comunicação, condições necessárias do conhecimento e da comunidade. Mas a construção do conhecimento e da comunidade é tarefa das pessoas, e não do equipamento tecnológico. $\dot{E}$ aqui que se situa, precisamente, o papel das novas tecnologias na educação. $A$ sua utilização devia libertar o tempo que agora é gasto em transmitir ou 
comunicar informação, permitindo que esse tempo fosse dedicado à construção de conhecimentos e vinculos sociais mais profundos.

$\mathrm{O}$ desenvolvimento da S. I. Não deve encaminhar-se para a criação ou reforço de hegenomias culturais, ideológicas ou económicas. Deverá, pelo contrário, estimular o diálogo na diversidade, a partilha de recursos culturais e a afirmação de cada povo ou cultura.

A S. I. é para todos, sendo crucial para isso o envolvimento intenso das comunidades escolares e da formação de educadores para essa nova sociedade.

\subsection{A Educação Tecnológica nas Escolas: educação geral ou profissionalizante?}

Tradicionalmente a oposição do conhecimento prático ao conhecimento teórico, foi responsável pela rejeição da tecnologia como disciplina escolar com o mesmo estatuto das demais. De qualquer forma, esta maneira de pensar sobre o ensino escolar revelou-se errada nas escolas.

Com o fim de justificar o interesse pela educação tecnológica (E.T.), os seus principais defensores afirmavam que se tornava necessário identificar e separar, em escolas particulares ou grupos, aqueles que podiam aprender melhor de uma forma prática. A ideia subjacente era esta: as pessoas "mais capazes" deveriam ser orientadas para aprender a saber, enquanto os "menos capazes" seriam orientados apenas para o fazer.

Isto contribuiu para uma redução do potencial das áreas práticas e tecnológicas do currículo e da sua contribuição para o ensino geral para todos.

Assim, na sequência deste debate, a tecnologia foi introduzida nos currículos escolares em muitos países, através de componentes técnicos ou profissionalizantes, restringindo-se apenas a uma área pequena, designada normalmente por Trabalhos Manuais, de forma a dar algum sabor tecnológico ao ensino geral.

Segundo Nash et al. (cit. por Reis, 1995: 34) esta falta de consenso acerca do papel da tecnologia nas escolas e sobre a questão de ela dever ser ou não dirigida educacionalmente para todos ou apenas vocacionalmente para alguns levantou obstáculos ao reconhecimento da disciplina, quer pelas entidades empregadoras quer pelo ensino superior.

Azevedo (1991: 189) escreve a este propósito: Prioritária é a criação de condições para quebrar a fatalidade ciclica com que, no nosso pais, vemos implantar-se um ensino tecnológico e profissional de segunda, via de deserdados, parentes pobres e socialmente discriminatário, sem investimentos técnico-financeiros e pedagógicos. No nosso país a Lei de 
Bases do Sistema Educativo (LBSE) consagra, no seu art..$^{\circ} 8^{\circ}$, a educação tecnológica, estabelecendo ser objectivo do ensino básico a educação tecnológica indispensável ao ingresso na vida activa e ao prosseguimento dos estudos, integrada numa formação geral e comum a oferecer a todos os cidadãos.

A questão básica que se coloca e que tem merecido acesa discussão é então a seguinte: a tecnologia deve fazer parte da educação dos alunos e como deve ser introduzida e desenvolvida no currículo ao longo da escolaridade? A tecnologia deve ser incluída no ensino técnico ou deve ser incorporada na educação geral de todos os alunos? Há algum tipo de relação entre estas duas opções?

Layton (cit. por Reis, 1995: 61) refere que a tecnologia tinha sido apenas um contribuinte marginal para a educação geral até há pouco tempo. Isto explica-se porque se identificava a educação tecnológica como profissionalização e preparação para uma ocupação específica, o que fez com que se desenvolvesse uma visão negativa e uma atitude de rejeição por parte da educação liberal em relação às matérias de teor tecnológico.

Contudo, a educação tecnológica começa progressivamente a afirmarse como algo diferente e mais abrangente do que o chamado ensino técnico ou profissional e começa a desenvolver-se também como uma área importante para a educação geral dos alunos. Apesar de tudo, a educação tecnológica como disciplina individualizada e integrada no ensino geral para todos é um fenómeno relativamente novo.

Mais recentemente, o número de pessoas interessado na educação tecnológica aumentou.

Muitos pedagogos têm defendido a ideia de que a tecnologia deve ter um lugar no currículo de todas as crianças, justificando-a com base em argumentos educacionais (o seu valor intrínseco e o seu valor no desenvolvimento das capacidades) e não em argumentos relacionados com o emprego ou a economia (como o fazem alguns sectores da indústria e dos próprios governos).

Outros autores apresentam apenas uma razão genérica bem simples para defenderem a inclusão de tecnologia na educação geral - se realmente existe um interesse na preparação dos alunos para viverem numa sociedade tecnológica, então a educação geral deve também incluir experiências de tipo técnico e pré-profissionais.

Por não ser objectivo do presente artigo o desenvolvimento exaustivo desta questão que temos vindo a tratar, vamos sintetizar em algumas linhas as ideias que nos parecem fundamentais e de acordo com Orpwood e Werdelin (1987, cit. por Reis, 1995: 62):

1. Embora a tecnologia não possua ainda o estatuto de disciplina estabelecida, um número crescente de pessoas defende, activamente, a 
introdução da tecnologia nas escolas como uma disciplina no ensino geral para todos, durante o período de escolaridade obrigatória;

2. Outros, continuam, no entanto, a defender ainda a ideia de que a tecnologia (através de vias profissionalizantes ou técnicas) é principalmente uma valiosa contribuição feita na escola para a preparação de uma carreira.

3. Para outros ainda terá de se caminhar para uma situação de compromisso, ou seja, a tecnologia seria primeiro ensinada como uma disciplina geral - tecnológica obrigatória para todos; mais tarde, seriam introduzidas especialidades (como a biotecnologia, a electrónica, a informática) que poderiam ser escolhidas pelos alunos em anos de escolaridade mais avançados;

4. De qualquer forma, o que acontece na realidade é que na grande maioria dos países o grande tema de actualidade é a crescente aceitação do lugar da tecnologia no ensino geral como uma disciplina para todos, integrando o período de escolaridade obrigatória.

\subsection{0 "novo" papel dos professores}

É no que se refere a este assunto que se tem gerado maior controvérsia. Para alguns, o professor "tradicional" não passa duma simples caricatura já que, segundo eles, se trata de um simples transmissor de informação e de comunicação, função que cada vez mais tem vindo a ser desempenhada pelas novas tecnologias de informação e comunicação.

Para outros o novo papel do professor como "treinador da aprendizagem" ou "facilitador" é mais tradicional do que geralmente se reconhece.

Pensamos que o desenvolvimento das novas tecnologias de informação e comunicação, embora modifique profundamente o papel do professor, já que não pode ser considerado como o único detentor dum saber, dada a generalização do mesmo, que lhe basta transmitir (passa de algum modo a ser um parceiro dum saber colectivo que deve organizar), em nada o seu papel fica diminuído.

A experiência tem demonstrado que a tecnologia mais avançada não tem qualquer utilidade para o sistema educativo, se este não estiver adaptado à sua utilização.

É, por isso, imprescindível que os professores estejam no perfeito domínio dos novos instrumentos pedagógicos. Daí a importância da formação contínua dos professores. A este propósito fala-se da necessidade duma nova alfabetização - a alfabetização informática (Relatório para a UNESCO de Comissão Internacional sobre Educação para o Século XXI, 1996: 166). Este documento refere sobre este assunto 
o seguinte: Esta "alfabetização informática" é cada vez mais necessária para se chegar a uma verdadeira compreensão do real. Ela constitui, assim, uma via privilegiada de acesso à autonomia, levando cada um a comportar-se em sociedade como um individuo livre e esclarecido.

$\dot{E}$ necessário um esforço pessoal e uma determinação firme de aprender os conhecimentos do ciberespaço. Entre muitas acções possiveis que a sociedade civil, através de associações e de sindicatos, ou o Estado, através de inúmeras estruturas ao seu alcance, devem promover, parece urgente a criação de programas universais e gratuitos de literacia tecnológica de aproximação à sociedade da informação, tendo em vista a actualização pessoal e a reconversão profissional.

A informatização das escolas leva alguns autores a desenharem cenários radicais quanto ao seu futuro. Contudo, pensamos que a escola $\mathrm{e}$ os professores serão tão ou mais necessários do que antes.

Por um lado, como refere Figueiredo (1995: 5) "a variedade explosiva da escolha e a agressividade crescente da oferta estão a mergulhar os cidadãos em geral, e as crianças em particular, na mais profunda das dissonâncias e ansiedades". Por outro lado, "a frieza das altas tecnologias impõe uma contrapartida indispensável de calor humano: quanto mais tecnológica é uma sociedade, mais necessita de compensações ao nível dos valores humanos e da afectividade (...). A função da escola reinventada: (...): fornecer a respostas humanas compensatórias de que a escola dos nossos dias se está a distanciar tão perigosamente".

Com o desenvolvimento dos novos meios de difusão, a informação deixou de ser predominantemente veiculada pelo professor na escola, mas a informação não é conhecimento, necessitando o aluno de ter a orientação de alguém que possua experiência no tratamento dessa informação.

As técnicas de informação e comunicação geram uma inesgotável fonte de informações. A função dos professores deverá ser ensinar os alunos a avaliar e gerir na prática a informação que lhes chega. Por isso, o desenvolvimento das novas tecnologias de informação e comunicação em nada diminui o papel dos professores, embora o modifique profundamente. Os professores tornam-se, de certo modo, parceiros de um saber colectivo que lhes compete organizar. Como já anteriormente se referiu, para a assunção deste novo papel é indispensável que a formação inicial e contínua lhes confira um domínio pleno destes novos instrumentos pedagógicos.

A revolução na sociedade da informação não dispensa, pois, o professor assim como os pais e a comunidade.

Marques (1998: 16) afirma: Perante uma imensa oferta de fontes de informação, de caminhos possiveis e de ritmos personalizados de aprendizagem, é essencial o papel do educador. Porventura já não 
precisa de ser depósito de informação, pois dispõe de recursos poderosos para aceder a toda a informação necessária. Também já não haverá espaço para atitudes de uma arrogante superioridade de quem tudo pode e sabe.

Não há dúvida que as novas tecnologias de informação e comunicação fornecem pistas para alcançar os objectivos educativos e abrem novas oportunidades à aprendizagem, que até há bem pouco tempo eram uma utopia.

As crianças e os adolescentes estão hoje a adquirir competências no uso da tecnologia multimédia interactiva, para utilizar o correio electrónico, para aceder a redes globais de computadores, ou seja, em poucas palavras: estão a trabalhar a níveis elevados de complexidade.

Contudo, embora tudo isto seja uma realidade (mais nos países desenvolvidos do que nos menos desenvolvidos), a educação formal tradicional contínua (e deve continuar) a desempenhar um papel de grande importância - a escola, enquanto instituição, e a presença pessoal do professor não podem ser substituídas pela tecnologia informática.

Os alunos se é certo que hoje estão a ter acesso a um vasto conjunto de informação e conhecimentos através das novas tecnologias de informação e comunicação, também é importante realçar que eles necessitam de estudar, de analisar, de reflectir, de trabalhar em grupo, ler livros, de lidar com o espaço real e, sobretudo, sublinhe-se: estabelecer um relacionamento (cooperativo e construtivo) com os seus semelhantes. As imagens multicoloridas e o mundo de magia que lhes é dado conhecer através dos ecrãs dos computadores não pode ser mais importante do que a vida cultural, económica e sobretudo social de cada um deles.

Em suma: as novas tecnologias de informação e comunicação modificarão certamente o papel do professor (e da educação formal tradicional), mas nunca o substituirão completamente. 


\section{BIBLIOGRAFIA}

AZEVEDO, J. (1991) A Educação Tecnológica nos anos 90, Porto, Edições ASA.

CARNEIRO, R. (1999) Portugal 2020, Lisboa, Edições Fenda.

CASTILHO, S. (1998) Manifesto para a Educação em Portugal, Lisboa, Texto Editora.

FOWELL, S. (1996) A crise na Educação e o papel das tecnologias de Informação, in A Educação do Futuro, o Futuro da Educação, Porto, Edições ASA, pp. 63-70.

MARQUES, R. (1998) Os desafios da sociedade da informação, in $\mathrm{Na}$ Sociedade da Informação, Colecção Perspectivas Actuais / Educação, Porto, Edições ASA, pp. 11-32.

REIS, M.F. (111995) Educação Tecnológica: a montanha pariu um rato?. Porto, Porto Editora.

SKILBECK, C. (1998) Os Sistemas Educativos face à Sociedade da Informação, in $\mathrm{Na}$ Sociedade da Informação, Colecção Perspectivas Actuais / Educação, Porto, Edições ASA, pp. 33-49.

TEDESCO, C. (1999) O Novo Pacto Educativo, Vila Nova de Gaia, Fundação Manuel Leão.

UNESCO (1998) Relatório Mundial da Educação, 1998: Professores e Ensino num Mundo em Mudança, Perspectivas Actuais, Porto, Edições ASA. 